\title{
PELATIHAN ARDUINO UNTUK SISWA SISWI MTS SWASTA AL-MURSYIDIYYAH BENDA BARU PAMULANG
}

\author{
${ }^{1}$ Kartika Sekarsari, ${ }^{2}$ Sunardi \\ Dosen Teknik Elektro Universitas Pamulang \\ Email : ${ }^{1}$ sekarsari.8910@gmail.com
}

\begin{abstract}
ABSTRAK
Arduino merupakan jenis mikrokontroller papan tunggal yang bersifat open-source. Prosesornya merupakan Atmel AVR dan softwarenya yang memiliki bahasa pemrograman sendiri menjadikan arduino mudah digunakan sebagai peralatan otomasi dan pengendali berbagai peralatan elektronika.

Didasari gagasan untuk menumbuhkan kreatifitas dikalangan siswa-siswi MTs agar mereka turut berpartisipasi dalam perkembangan teknologi dan kelak dapat menciptakan teknologi baru berbasis Arduino yang berguna bagi masyarakat, maka dosen dan mahasiswa dari Prodi Teknik Elektro Universitas Pamulang melakukan kegiatan Pengabdian Kepada Masyarakat (PKM) di Sekolah MTs Swasta Al-Mursyidiyyah Benda Baru Pamulang. Pelaksanaan PKM ini berupa edukasi pelatihan mikrokontroller arduino yang meliputi: pengenalan dasar komponen elektronika dan arduino, pengenalan dasar pemrograman arduino IDE, dan cara merangkai komponen elektronika dengan Arduino.

Pelatihan arduino yang dikemas sedemikian rupa dalam bentuk yang menyenangkan dan mudah difahami ini ternyata mampu menciptakan kegiatan pelatihan yang memenuhi unsur-unsur pengetahuan, keterampilan, teknik, sikap, dan etika siswa-siswi MTs Al Mursyidiyyah dalam menerima materi pelatihan. Selain itu, peserta juga mampu mengenali komponen elektronika dan arduino, mampu mengupload program arduino IDE kedalam mikrokontroller, dan mampu merepresentasikan pengetahuan baru yang mereka peroleh kedalam bentuk eksperimen perakitan komponen elektronika menggunakan arduino secara mandiri dan berhasil.
\end{abstract}

\section{Kata Kunci: Teknologi, Mikrokontroller, Arduino, Pelatihan}

\section{PENDAHULUAN}

Pemberdayaan masyarakat adalah upaya untuk memberikan daya (empowerment) atau penguatan (strengthening) kepada masyarakat. Pemberdayaan masyarakat juga diartikan sebagai kemampuan individu yang bersenyawa dengan masyarakat dalam membangun keberdayaan masyarakat yang bersangkutan sehingga bertujuan untuk menemukan alternative - alternatif baru dalam pembangunan masyarakat.[1]. Pemberdayaan masyarakat harus dibangun bersamasama antara akademisi dan industri, sehingga timbul sinergi antara keduanya dalam berpartisipasi melaksanakan kegiatan sosial ditengah masyarakat untuk 
mewujudkan perkembangan pengetahuan, pengalaman, dan keahlian di dalam masyarakat.

Pada saat ini Indonesia sudah masuk dalam era globalisasi, dimana salah satunya ditandai dengan mudahnya masyarakat mendapatkan informasi dari berbagai belahan dunia sebagai akibat dari perkembangan teknologi yang demikian pesat.[2] Hal ini dapat memberikan dampak positif dan negatif, tergantung dari seberapa banyak informasi yang dapat diterima dan difilter oleh masyarakat. Oleh sebab itu, pemberdayaan masyarakat yang berkaitan dengan informasi dan perkembangan teknologi, seperti: sosialisasi dan pelatihan-pelatihan teknologi perlu dilakukan agar perkembangan teknologi dapat dimanfaatkan sebaik-baiknya sehingga berdampak positif pada masyarakat.

Ditengah pesatnya perkembangan teknologi khususnya teknologi informasi dan komunikasi (TIK) inilah lahir dan tumbuh generasi yang dikenal dengan istilah generasi Milenial. Generasi ini dianggap sebagai generasi yang lebih akrab dengan teknologi, karena generasi ini tumbuh di era teknologi yang telah menyentuh setiap sendi kehidupan.[3] Agar perkembangan teknologi ini berdampak positif dikalangan masyarakat khususnya anak-anak remaja usia sekolah atau generasi Milenial, maka dalam hal pendidikan dan pengajaran siswa-siswa disekolah perlu dikenalkan dengan teknologi yang dibangun dari komponen-komponen elektronika dan mikrokontroller. Hal ini didasari karena banyak dari perkembangan teknologi khususnya TIK yang ada sekarang adalah hasil dari perancangan rangkaian elektronik dengan mikrokontroller atau mikrokomputer. Dengan demikian, diharapkan perkembangan teknologi akan mampu di ikuti oleh siswa-siswa sekolah untuk ikut menciptakan lahirnya inovasi-inovasi baru dalam pembuatan peralatan teknologi yang dapat membantu manusia untuk menyelesaikan pekerjaannya.

Mikrokontroler adalah peralatan elektronika yang berbentuk chip yang memiliki masukan dan keluaran serta kendali, dimana cara pemrogramannya bisa ditulis dan dihapus dengan cara khusus. Mikrokontroler ini banyak digunakan untuk mengendalikan peralatan - peralatan elektronik. Salah satu jenis mikrokontroller yang ada adalah Arduino. Arduino merupakan jenis mikrokontroller yang memiliki hardware berupa prosesor Atmel AVR dalam bentuk pengendali mikro single-board bersifat open-source. Oleh karena sifat software arduino yang open source, membuat arduino yang memiliki bahasa pemrograman sendiri tersebut dapat diakses dan dimodifikasi oleh siapapun sehingga pemanfaatannya menjadi lebih luas terutama untuk mengendalikan berbagai rangkaian elektronik.

Oleh karena, pemrograman Arduino mudah dipelajari oleh siapa saja bahkan oleh anak-anak usia sekolah sekalipun, dan sejalan dengan misi Yayasan Pendidikan Islam Al-Mursyidiyyah tempat dimana sekolah yang menjadi mitra kegiatan PKM ini berada, yakni menumbuh kembangkan bakat dan minat siswa melalui kegiatan kokulikuler, ekstrakurikuler yang variatif, dan berbasis kemasyarakatan, maka pelaksanaan kegiatan Pengabdian Kepada Masyarakat yang diusulkan oleh dosen bersama mahasiswa dari Program Studi Teknik Elektro Universitas Pamulang mengambil judul "Pelatihan Arduino untuk Siswa Siswi MTs Swasta Al-Mursyidiyyah Benda Baru Pamulang”. 
Tujuan dari kegiatan Pengabdian Kepada Masyarakat (PKM) ini selain untuk melaksanakan Tri Dharma Perguruan Tinggi juga sebagai sarana pengabdian ke ilmuwan, keahlian dan ketrampilan bidang elektronika dari dosen-dosen serta mahasiswa S-1 Prodi Teknik Elektro Universitas Pamulang, kepada siswa siswi MTs Swasta Al-Mursyidiyyah. Kegiatan PKM ini juga bertujuan memperkenalkan arduino kepada siswa - siswi MTs Swasta Al-Mursyidiyyah dalam bentuk edukasi workshop dengan harapan dapat menumbuhkan daya kreativitas dan inovasi siswa sehingga meningkatkan pengetahuan, sikap, dan keterampilan siswa-siswi MTs Swasta Al-Mursyidiyyah dalam hal perancangan rangkaian elekronik berbasis Arduino.

Manfaat yang diharapkan untuk peserta pelatihan dalam kegiatan PKM yang dilaksanakan di sekolah MTs Swasta Al-Mursyidiyyah adalah sebagai berikut: a. Membuka wawasan, informasi, dan pengetahuan dikalangan siswa - siswi MTs AlMursyidiyyah mengenai pengetahuan bidang elektronika, serta teknologi yang dihasilkan.

b. Melatih siswa-siswi MTs Al-Mursyidiyyah mengenai keterampilan dasar dalam mengenal berbagai jenis komponen elektronika dan cara merakitnya.

c. Melatih siswa-siswi MTs Swasta Al - Mursyidiyyah mengenai keterampilan dalam merakit dan mengupload program pada Arduino.

d. Menumbuhkan ide - ide kreatif dalam hal perancangan komponen elektronika menggunakan mikrokontroller arduino.

\section{METODE PELAKSANAAN KEGIATAN}

Pembelajaran merupakan suatu proses penciptaan lingkungan yang memungkinkan terjadinya proses belajar. Belajar merupakan aktivitas dari peserta didik/siswa dalam berinteraksi dengan lingkungan yang menghasilkan perubahan perilaku yang bersifat konstan. Belajar pada dasarnya untuk mencari: [4]

(a) Pengetahuan

(b) Keterampilan

(c) Teknik

(d) Sikap

(e) Pengalaman

Hendaknya, kelima parameter diatas menjadi dasar pendidikan di era digitalisasi seperti saat ini, dimana peran pendidik dalam mendidik peserta didik / siswa sangatlah dibutuhkan. Selain pendidik dituntut untuk menguasai informasi yang berkaitan dengan perkembangan teknologi, mereka diharapkan mampu menciptakan kegiatan belajar mengajar di kelas yang dapat memenuhi unsur-unsur pengetahuan, keterampilan, teknik, sikap, dan etika peserta didik dalam menerima ilmu di sekolah. Salah satu bentuk yang cocok untuk generasi ini diantaranya penggunaan teknologi dalam pembelajaran. Penggunaan teknologi dengan pembelajaran yang disajikan sedemikian rupa oleh para pendidik terhadap peserta didik/siswa, menjadi sarana para siswa untuk mencurahkan segala kemampuannya Pelaksanaan kegiatan Pengabdian Kepada Masyarakat (PKM) ini bertempat di 
Sekolah MTS Swasta AL-Mursyidiyyah yang terletak di Jalan, Siliwangi RT.003/018 dan dilaksanakan pada tanggal 20 - 21 November 2019

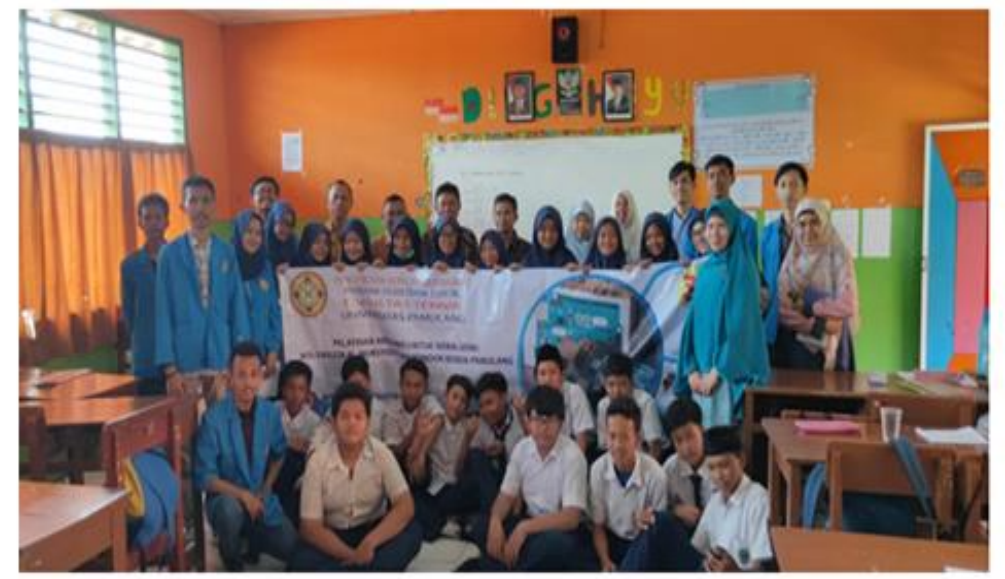

Gambar 1. Pelaksanaan Kegiatan PKM di MTs Swasta Al - Mursyidiyyah Pamulang

Metode pelatihan Arduino yang dilakukan dalam pelaksanaan kegiatan Pengabdian Kepada Masyarakat (PKM) ini meliputi 3 metode yaitu:

\section{a. Pengenalan komponen elektronika dan Arduino.}

Pada tahap ini siswa diberikan materi mengenai pengenalan berbagai komponen elektronika dan arduino, cara kerja dari komponen-komponen tersebut, dan penerapannya untuk berbagai peralatan elektronik serta pengaplikasian dalam rangkaian arduino yang dapat dilihat secara langsung maupun melalui materi berupa slide atau gambar. Tujuan dari penyampaian materi pada tahap ini, selain untuk memberikan motivisai peserta didik/siswa agar dapat membangkitkan keinginan serta minat untuk berkreatifitas, juga untuk membangkitkan rangsangan dalam kegiatan belajar, sehingga membawa pengaruh-pengaruh psikologis secara positif terhadap siswa. Materi pelatihan Arduino disampaikan dalam bentuk presentasi Power Point didepan kelas, dan hardcopy yang dibagikan kepada para siswa.

Selain itu, pada tahap ini siswa-siswi juga dikenalkan dengan demonstrasi aplikasi arduino yang diterapkan pada rangkaian elektronik, diantaranya adalah: tempat sampah otomatis, bel cerdas cermat berbasis arduino, dan alat ukur komponen elektronika berbasis arduino.

\section{b. Pengenalan dasar pemrograman Arduino IDE.}

Pada tahap ini siswa dikenalkan dan dilatih untuk membuat pemrograman arduino pada komputer dan meng-upload program. Pelatihan pemrograman ini selain dimaksudkan untuk membiasakan siswa dalam berinteraksi dengan komputer, juga untuk melatih siswa membuat pemrograman sederhana menggunakan Arduino IDE yang nantinya dapat di upload ke dalam mikrokontroller arduino itu sendiri. Dalam tahap ini pengenalan dasar pemrograman Arduino IDE dibuat dengan lebih mudah dan menyenangkan 
sehingga peserta yang terdiri dari siswa-siswi MTs Swasta Al-Mursyidiyyah akan lebih bersemangat dalam mempelajari arduino.

\section{c. Cara merangkai Arduino}

Pada tahap ini siswa diajarkan cara menggunakan bagian-bagian dari papan arduino uno yang terdiri dari :memori, konfigurasi port I/O (Port input /Output) baik analog maupun digital, tegangan kerjanya, dan semuanya yang menyangkut hardware termasuk dalam merangkai komponen elektronika sederhana seperti: kombinasi Led, Buzer, dan penggunaan sensor ultrasonic yang diaplikasikan dengan menggunakan arduino. Tujuan dalam tahapan ini adalah memperkenalkan siswa mengenai; cara merangkai komponen elektronika dan arduino dengan membaca skema diagram pengkawatan rangkaian yang telah dibuat sebelumnya didalam kertas, dan cara menggunakan project board yaitu suatu papan percobaan yang tidak perlu menggunakan solder dan timah dalam menyambungkan antara komponen satu dengan yang lain dalam rangkaian.

Untuk melihat kegiatan PKM pelatihan Arduino ini dapat di pahami oleh seluruh peserta pelatihan, maka para mentor yang terdiri dari mahasiswa teknik elektro pada akhir acara memberikan sebuah game berupa pertanyaanpertanyaan kepada peserta seputar materi-materi pelatihan yang telah diberikan sebelumnya

\section{HASIL DAN PEMBAHASAN}

Hasil yang diperoleh dalam kegiatan Pengabdian Kepada Masyarakat (PKM) bertema Pelatihan Arduino untuk siswa-siswi MTs Al-Mursyidiyyah Pondok Benda Pamulang, dapat di uraikan sebagai berikut:

\section{Pengenalan Arduino}

Siswa-siswi sangat antusias dalam mendengarkan pemaparan materi pengenalan komponen - komponen elektronika dan arduino yang dilakukan oleh mahasiswa elektro didepan kelas. Pemaparan materi yang disampaikan dalam

tiga cara yakni presentasi, ceramah, dan mentoring seperti yang terlihat dalam gambar-2 membuat siswa siswi merasa nyaman dan tidak merasa bosan dalam mengikuti pelatihan
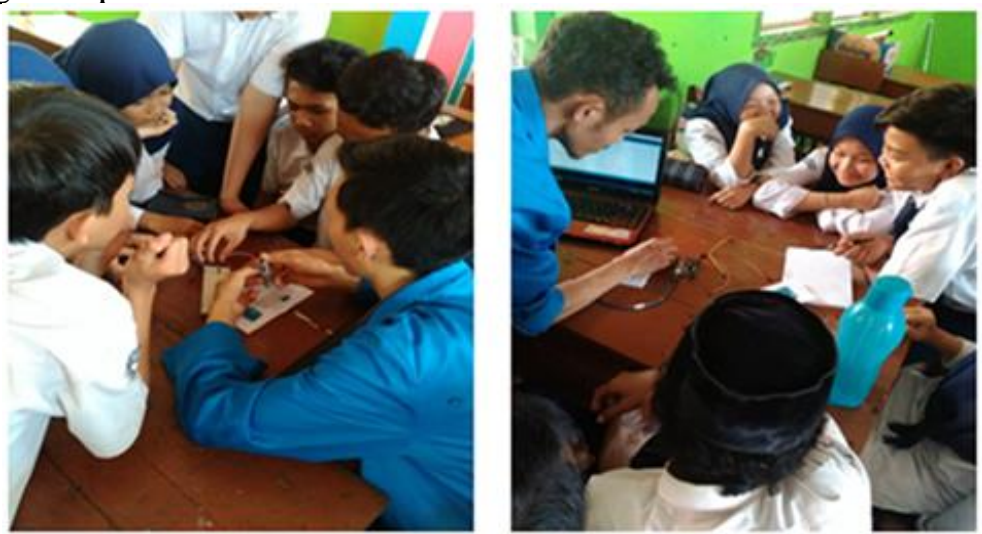

Gambar 2. Pengenalan Komponen elektronika dan Arduino 


\section{Mengenalkan dasar pemrograman Arduino IDE}

Pengenalan pemrograman Arduino IDE dalam kelompok-kelompok mentoring menjadikan siswa-siswi dapat berinteraksi secara langsung dengan para mentoring untuk belajar cara mengupload program arduino IDE kedalam mikrokontroller.

\section{Merangkai komponen - komponen elektronika dan arduino}

Pelatihan cara merangkai komponen elektronika dan arduino yang dilakukan dalam kelompok mentoring dengan dipandu oleh para mentoring dalam kelompok-kelompok, seperti yang terlihat dalam gambar-3 menjadikan siswa siswi MTs Al-Mursyidiyyah terlibat langsung didalam pelatihan tersebut. Selanjutnya, dengan memberikan kesempatan secara langsung kepada siswa siswi MTs Al-Mursyidiyyah untuk melakukan uji coba sendiri dalam merangkai komponen - komponen elektronika dan arduino, menjadikan siswa siswi mampu merepresentasikan materi yang mereka dapatkan pada saat pelatihan dalam bentuk eksperimen dan percobaan yang nyata dengan rangkaian yang dapat bekerja secara maksimal.

\section{KESIMPULAN DAN SARAN}
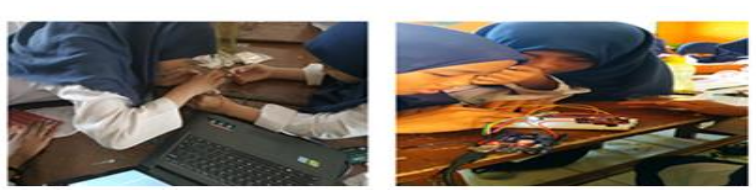

Kegiatan

Pengabdian Kepada Masyarakat (PKM) yang dilaksanakan oleh dosen - dosen dan mahasiswa dari Prodi Teknik

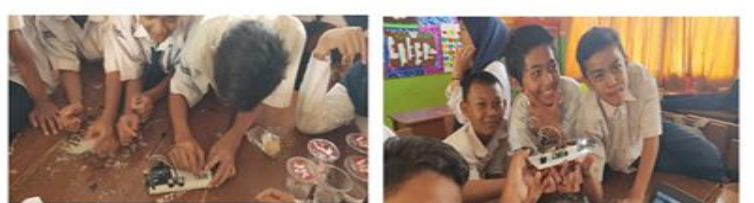

Gambar 3. Merangkai Komponen Elektonika dan Arduino
Elektro dan berlokasi di sekolah MTs Swasta Al-Mursyidiyyah berjalan dengan lancar dan menghasilkan beberapa point kesimpulan sebagai berikut:

a. Pelatihan Arduino untuk siswa siswi MTs Al-Mursyidiyyah yang terdiri dari: pengenalan komponen elektronika dan arduino, pelatihan mengupload program arduino IDE, dan pelatihan merangkai komponen elektronika dengan arduino, mampu menciptakan kegiatan pelatihan yang memenuhi unsur-unsur pengetahuan, keterampilan, teknik, sikap, dan etika peserta didik dalam menerima materi pelatihan.

b. Pelatihan yang dikemas secara menarik dan menyenangkan, ternyata membuat siswa mampu menyerap materi yang diajarkan secara lebih cepat, seperti; mampu mengenali komponen elektronika dan arduino, serta mampu mengupload program arduino IDE kedalam mikrokontroller.

c. Kesempatan yang diberikan kepada siswa-siswi untuk mencoba sendiri dalam merangkai komponen-komponen elektronika dan arduino, serta mengupload program arduino IDE sesuai dengan panduan yang telah diberikan sebelumnya, mampu membuat siswa mencurahkan segala kemampuannya dalam bereksperimen dan berhasil. 
Saran yang disampaikan dari hasil kegiatan PKM bahwa dengan melihat antusiasme siswa - siswi MTs Al Mursyidiyyah dalam mengikuti pembelajaran dan pelatihan yang berbasis teknologi seperti pelatihan arduino ini, diharapkan pelatihan berbasis teknologi dapat dilakukan secara kontinyu dengan berbagai macam bentuk pelatihan atau workshop yang lain.

\section{DAFTAR PUSTAKA}

A Sobarna, S Hambali, S Sutiswo, D Sunarsi. (2020). The influence learning used $\mathrm{ABC}$ run exercise on the sprint capabilities. Jurnal Konseling dan Pendidikan 8 (2), 67-71

Abdul Kadir, 2015 Zero to a Pro Arduino Panduan Mempelajari Aneka Proyek Berbasis Mikrokontroller. Andi Yogyakarta.

Badan Pusat Statistik. 2018. Statistik Gender Tematik, Profil Generasi Milenial Indonesia. Kementrian Pemberdayaan Perempuan dan perlindungan Anak.

Kalfaris Lalo, 2018 .Menciptakan Generasi Milenial Berkarakter dengan Pendidikan karakter Guna Menyongsong Era Globalisasi. Jurnal Ilmu Kepolisian.Vol 12.No.2. Juli 2018.

Mardikanto, Totok. 2014. CSR (Corporate Social Responsibility) (Tanggung jawab Sosial Korporasi). Bandung: Alfabeta.

Rusti Lumban Gaol, 2015. Peningkatan Kualitas Pembelajaran Listrik Dinamis melalui Implementasi Virtual laboratorium Berbasis Komputer di SMPN 9 Tebing Tinggi, Jurnal Teknologi \& komunikasi dalam Pendidikan Vol 2 No 1 Juni 2015 p-ISSN 2355-4983; e-ISSN:2407-7488.

Sunarsi, D., \& Asmalah, L. (2018). Pelatihan Manajemen Pengembangan Diri Bagi Penerima Beasiswa RZIS UGM Dan Dompet Shalahuddin Jogjakarta. Jurnal Pengabdian Dharma Laksana, 1(1), 51-60.

Sunarsi, D., Kusjono, G., \& Nuryana, I. (2019). Pelatihan Manajemen Penguasaan Kelas Dan Pembuatan Bahan Ajar Bagi Tenaga Pengajar Sukarela Taman Belajar Kreatif Mekarsari. Jurnal Pengabdian Dharma Laksana, 2(1), 41-44.

Sunarsi, D., Kustini, E., Lutfi, A. M., Fauzi, R. D., \& Noryani, N. (2019). Penyuluhan Wirausaha Home Industry Untuk Meningkatkan Ekonomi Keluarga Dengan Daur Ulang Barang Bekas. BAKTIMAS: Jurnal Pengabdian pada Masyarakat, 1(4), 188-193.

Susanto, S., Sarwani, S., \& Afandi, S. (2018). Analisis Kinerja Keuangan Untuk Mengetahui Tingkat Kesehatan, Pertumbuhan Dan Prospek Usaha Pada Unit Usaha Koperasi (Studi Kasus Koperasi Awak Pesawat Garuda Indonesia di Tangerang). INOVASI, 1(1).

Yuyun Elizabeth Patras, Ini Tantangan Guru Mengajar Siswa Milenial, https://almursyidiyyah.webs.com/, diakses tanggal 15 oktober 2019

https://www.republika.co.id/berita/pendidikan/eduaction/18/02/03/p3kdiu374-initantangan - guru -mengajar - siswa-milenial, di akses tanggal 20 oktober 2019 